\title{
Willingness by people living with HIV/AIDS to utilize HIV services provided by Village Health team workers in Kalungu district, central Uganda
}

\author{
Mutaawe Lubogo ${ }^{1}$, Ronald Anguzu ${ }^{2,5}$, Humphrey Wanzira ${ }^{3}$, Irene Namugwanya ${ }^{1}$, \\ Oliver Namuddu ${ }^{1}$, Denis Ssali ${ }^{1}$, Sylivia Nanyonga ${ }^{1}$, Josephine Ssentongo ${ }^{4}$, Janet Seeley ${ }^{4}$
}

1. District Health Team, Kalungu District Local Government

2. Makerere University School of Public Health (MakSPH)

3. Ministry of Health, Uganda $(\mathrm{MoH})$

4. Medical Research Council / Uganda Virus Research Institute (MRC/UVRI), Uganda

5. El-Channun Community Health Initiatives, Uganda (ELCOHIN)

\begin{abstract}
Background: Less than one quarter of people in need have access to HIV services in Uganda. This study assessed willingness of people living with HIV/AIDS (PLWHAs) to utilize HIV services provided by Village Health Teams (VHTs) in Kalungu district, central Uganda.

Methods: A cross-sectional study conducted in two health facilities providing anti-retroviral therapy enrolled 312 PLWHAs. Pre-tested semi-structured questionnaires were administered to participants at household level. A forward fitting logistic regression model computed the predictors of willingness of PLWHAs to utilize services provided by VHTs.

Results: Overall, $49 \%$ were willing to utilize HIV services provided by VHTs increasing to $75.6 \%$ if the VHT member was HIV positive. PLWHAs who resided in urban areas were more likely to utilize HIV services provided by VHTs (AOR 0.24, 95\%CI 0.06-0.87). Barriers to utilizing HIV services provided by VHTs were: income level > 40 USD (AOR 6.43 95\%CI 1.19-34.68), being a business person (AOR 8.71 95\%CI 1.23-61.72), peasant (AOR 7.95 95\%CI 1.37-46.19), lack of encouragement from: peers (AOR 6.33 95\%CI 1.43-28.09), spouses (AOR 4.93 95\%CI 1.23-19.82) and community leader (AOR 9.67 95\%CI 3.35-27.92).

Conclusion: Social support could improve willingness by PLWHAs to utilize HIV services provided by VHTs for increased access to HIV services by PLWHA.

Keywords: Willingness by people living with HIV/AIDS to utilize HIV services provided by Village Health Team workers in Kalungu district, central Uganda

DOI: https://dx.doi.org/10.4314/ahs.v17i1.27

Cite as: Lubogo M, Angu₹u R, Wanzira H, Namugwanya I, Namuddu O, Ssali D, Nanyonga S, Ssentongo J, Seeley J. Willingness by people living with HIV/AIDS to utilize HIV services provided by Village Health team workers in Kalungu district, central Uganda. Afri Health Sci. 2017;17(1): 216-224. https:// dx.doi.org/10.4314/abs.v17i1.27
\end{abstract}

\section{Background}

An estimated 33.3 million people are living with HIV globally, $67 \%$ of whom reside in sub-Saharan Africa. This region accounts for almost $70 \%$ of 1.7 million HIV-related deaths that occurred in $2011^{1}$. Uganda is one of the countries with an increasing number of People Living with HIV/AIDS (PLWHAs) partly due to new infections

\section{Corresponding author: \\ Ronald Anguzu \\ Makerere University, \\ School of Public Health, \\ P.O. Box 7072, Kampala, Uganda. \\ Email: ranguzu@musph.ac.ug}

and longevity due to the widespread use of Anti-retroviral Therapy (ART) ${ }^{2}$. The increasing demand for HIV services in many African countries is currently hampered by health systems inadequacies leading to limited access to many patients in need. In order to address this, community health workers that exist in most countries have not only contributed to the improvement of Maternal, Newborn and Child health $(\mathrm{MNCH})$ indicators but also to general HIV care and treatment especially in rural communities ${ }^{3,4}$. Organizations have engaged community health workers in counseling, home-basedcare, health education, adherence support and livelihood support for PLWHAs. Desirable outcomes of this include a reduction in the work load on health workers and also reduction in the waiting time for PLWHAs to access HIV services ${ }^{5,6}$.

African Health Sciences Vol 17 Issue 1, March, 2017 
Community health workers can therefore be used as a vehicle to increase access to HIV services in the context of increasing demand for such services with limited human resources for health to provide such services ${ }^{7,8}$. Task shifting in health care systems in many African countries has been used to offer quality, cost-effective care to more PLWHA than a physician-centeredmodel because it reduces the work load among the health workers offering HIV care and managemen ${ }^{t, 10}$. Engaging community health workers to offer basic HIV services to PLWHA is potentially one of the avenues to improve access to services consequently reducing work load among health workers and improving adherence to $\mathrm{ART}^{7,8}$.

Studies have shown that in a number of different settings there is no significant difference in the quality of care of patients who receive services from community health workers compared to those receiving health facility based care ${ }^{5,11-13}$. In addition, there is no evidence to show if the PLWHAs are ready to utilize HIV services provided by community health workers of either sero-status.

In Uganda, Kalungu is a district with one of the highest HIV prevalence rates in Uganda with only $20 \%$ of its population having access to HIV services and which would benefit from the use of community health workers in providing HIV services. Village Health Teams (VHTs) are made up of community members trained in basic health care skills. This study was therefore conducted to assess the willingness of PLWHAs in this district to utilize HIV services provided by community health workers, in the context of VHTs.

\section{Methods \\ Study design}

A cross-sectional study was conducted in two health facilities in Kalungu district. These were Bukulula Health Centre (HC) IV and Kalungu HCIII.

\section{Study setting}

Kalungu district has two admisitrative units or health sub-districts (HSDs) i.e. Kalungu East and Kalungu West. Kalungu has one HCIV and 19 HCIII's according to Uganda's Ministry of Health referral hierachy. All facilities at HCIII and IV level are antiretroviral treatment (ART) centres serving a population of 30,000 PLWHAs. Kalungu HCIII and Bukulula HCIV are the biggest ART centres in Kalungu with 10,000 and 20,000 registered PLWHA respectively. These two ART centers have a nurse-to-patient ratio of 1:300 with 100 VHTs covering 25 villages. The main role of village health teams is to sensitize and educate patients on general health services on a monthly basis. Bukulula HCIV has 1019 and 43 PLWHA on first and second line ART respectively while 49 are active clients on pre-ART care. Kalungu HCIII has 512 and 72 PLWHA on first and second line ART respectively while 29 are active clients on pre-ART care.

Regarding staffing levels, Bukulula HCIV has one medical offier and six enrolled nurses trained in HIV care and management. It has two peer counsellors who offer adherence counseliing to HIV positive patients and a dedicated laboratory with lab workers trained to conduct rapid diagnostic tests and CD4+ cell counting. On the other hand, Kalungu HCIII has only two clinicians and three nurses who offer HIV counseling, testing and treatment services. Blood samples are transported to Bukulula for CD4+ cell testing and to Kampala for viral load (VL) testing

\section{Sample size and enrolment of participants}

A modified Kish Leslie formula (1965) was used to estimate the sample size required ${ }^{14}$. A total of 290 respondents were computed using a 75\% acceptance rate ${ }^{15}, 95 \%$ confidence interval, a precision of $5 \%$. A factor of $10 \%$ of the sample size was included to cater for non-response bringing the total sample size to 320 .

Simple random sampling of registered HIV positive patients seeking care was conducted from each of the sites. Those who had not attended these facilities on three consecutive visits were excluded. Probability proportionate to size sampling was applied to determine the number of PLWHA to be selected for interviews at each ART sites.

Inclusion criteria included PLWHAs aged 18 years and above receiving HIV services in Bukulula HCIV and Kalungu HCIII while those who did not consent or too sick to participate were excluded.

\section{Study measurements}

Willingness by PLWHA to utilize HIV services offered by VHTs was a binary outcome variable categorized as a 'Yes' and 'No'. Independent variables that were elicited from the participants included social demographic characteristics including information related to their ART orientation. Community factors like peer encouragement, 
partner/spouse encouragement and community leader encouragement were also measured as binary outcomes "Yes" for those who had been encouraged by peer, partner/spouse and community leader respective while "No" was coded for those who answered otherwise.

\section{Data collection}

Data was collected by use of pre-tested structured questionnaires that were administered by trained interviewers. These tools contained questions on the respondents' socio-demographic characteristics and other plausible and explanatory variables. Quantitative data was collected from April to May 2014. Tools with collected data were field edited by the principal investigator in order to ensure quality control by checking for missing fields among other checks.

\section{Statistical analysis}

Double data entry and cleaning of data was done in Epi info 3.5.1 which was then exported to STATA version 12.0 for statistical analysis. Descriptive statistics was conducted and presented using frequencies and percentages. A multi-variable logistic regression model was used to determine the association between independent factors and willingness of participants to utilize HIV services provid- ed by VHTs. Odds ratios with their corresponding 95\% confidence intervals were presented. In all analyses, a $\mathrm{p}<$ 0.05 was considered statistically significant.

\section{Ethical considerations}

Ethical approval to conduct this study was obtained from the Uganda National Council for Science and Technology in April 2014. Privacy and confidentiality of respondent information was upheld by the research team. Informed consent was sought and obtained from all respondents before conducting any interview. Respondent anonymity was observed through use of questionnaire identification numbers. Permission to carry out this study in Kalungu district was obtained from Kalungu district administration.

\section{Results}

Socio-demographic characteristics of study participants

A total of 320 participants were recruited in the study, however 9 were dropped from the analysis because they did not complete the interviews. Overall, 49\% (43.4356.42 ) of the study participants were willing to utilize HIV services provided by VHTs. This proportion increased to $75.6 \%(70.76-80.36)$ if the VHT member was HIV positive (Table 1). 


\begin{tabular}{|c|c|c|}
\hline Variable & Willing, n (\%) & Not willing, n (\%) \\
\hline \multicolumn{3}{|l|}{ Age group (years) } \\
\hline $0-20$ & $3(1.9)$ & $11(7.1)$ \\
\hline $21-40$ & $87(57.6)$ & $92(59.4)$ \\
\hline $41-60$ & $50(33.1)$ & $46(29.7)$ \\
\hline$>60$ & $11(7.3)$ & $6(29.7)$ \\
\hline \multicolumn{3}{|l|}{ Sex } \\
\hline Male & $41(26.9)$ & $41(25.9)$ \\
\hline Female & $111(73.0)$ & $117(74.1)$ \\
\hline \multicolumn{3}{|l|}{ Marital status } \\
\hline Single & $15(9.9)$ & $23(14.6)$ \\
\hline Married/living together & $77(50.7)$ & $72(45.6)$ \\
\hline Separated/Widowed & $60(39.5)$ & 63 (39.9) \\
\hline \multicolumn{3}{|l|}{ Religion } \\
\hline Roman Catholic & $97(64.2)$ & $106(67.1)$ \\
\hline Protestant/Pentecostal & 33 (21.9) & $31(19.6)$ \\
\hline \multirow{2}{*}{\multicolumn{3}{|c|}{ Tribe }} \\
\hline & & \\
\hline Ganda & $101(68.3)$ & $113(73.4)$ \\
\hline Munyankole/Mutooro & $17(11.5)$ & $15(9.8)$ \\
\hline Rwandese & $30(20.3)$ & $26(16.9)$ \\
\hline \multicolumn{3}{|l|}{ Education } \\
\hline None & $16(10.6)$ & $21(13.3)$ \\
\hline Primary & $111(73.5)$ & $104(65.8)$ \\
\hline Post primary & $24(15.9)$ & $33(20.8)$ \\
\hline \multicolumn{3}{|l|}{ Residence } \\
\hline Rural & 107 (70.4) & $111(70.3)$ \\
\hline Semi-Urban & $45(29.6)$ & $47(29.8)$ \\
\hline \multicolumn{3}{|l|}{ Occupation } \\
\hline Formal & $18(12.1)$ & $12(7.7)$ \\
\hline Peasant & $104(69.8)$ & $113(72.9)$ \\
\hline Business & $27(18.1)$ & $30(19.4)$ \\
\hline \multicolumn{3}{|l|}{ Income level (USD) } \\
\hline$<20$ & $108(72.5)$ & 112 (70.9) \\
\hline $20-40$ & $27(18.1)$ & $26(16.5)$ \\
\hline$>40$ & $14(9.4)$ & $20(12.7)$ \\
\hline \multicolumn{3}{|l|}{ On ART } \\
\hline Yes & $135(90.0)$ & $140(88.6)$ \\
\hline No & $15(10.0)$ & $18(11.4)$ \\
\hline \multicolumn{3}{|l|}{ Period in HIV care (years) } \\
\hline$<1$ & $13(8.6)$ & $22(14.0)$ \\
\hline$\geq 1$ & $139(91.5)$ & $135(85.9)$ \\
\hline \multicolumn{3}{|l|}{ Distance to health facility in $\mathbf{~ k m}$} \\
\hline$<10$ & $117(76.9)$ & 109 (68.9) \\
\hline$\geq 10$ & $35(23.0)$ & $49(31.0)$ \\
\hline \multicolumn{3}{|l|}{ Ever sought VHT services } \\
\hline Yes & $90(59.6)$ & $81(53.3)$ \\
\hline No & $61(40.6)$ & $71(46.7)$ \\
\hline \multicolumn{3}{|l|}{ Peer encouragement } \\
\hline Yes & $133(89.7)$ & $43(28.3)$ \\
\hline \multirow{2}{*}{\multicolumn{3}{|c|}{ Spouse/partner encouragement }} \\
\hline & & \\
\hline Yes & 104 (83.9) & $27(20.5)$ \\
\hline & $20(16.1)$ & $105(79.6)$ \\
\hline \multicolumn{3}{|l|}{ Community leader encouragement } \\
\hline Yes & 125 (83.9) & $40(25.6)$ \\
\hline No & $24(16.1)$ & $116(74.4)$ \\
\hline
\end{tabular}

Of the respondents willing to utilize HIV services provided by VHTs $33.1 \%$ of them were aged $41-60$ years (mean age 31.76 and standard deviation of 9.30), $73 \%$ were female, $50 \%$ were married, $95 \%$ were Roman catholic, $73 \%$ had completed primary level education, $70 \%$ were resident in urban areas, $69.8 \%$ were peasants living on less than one USD per day $(75.5 \%)$. Majority of the respondents $(91.1 \%)$ had spent more than one year in HIV care and management while $90 \%$ of them were on ART. Even when majority of them had been encouraged by their peers, spouse or community leader to utilize the HIV services provided by the VHTs, only 59\% had sought VHT services for any other reason other than HIV services (Table 2). 


\begin{tabular}{|c|c|c|}
\hline Variable & Crude OR (95\%CI) & Adjusted OR (95\%CI) \\
\hline \multicolumn{3}{|l|}{ Age groups (years) } \\
\hline $0-20$ & 1 & 1 \\
\hline $21-40$ & $0.3(0.1-1.2)$ & $0.2(0.02-3.1)$ \\
\hline $41-60$ & $0.3(0.1-0.9)$ & $0.3(0.01-4.2)$ \\
\hline$>60$ & $0.2(0.03-0.75)$ & $0.1(0.01-2.1)$ \\
\hline \multicolumn{3}{|l|}{ Sex } \\
\hline Male & 1 & 1 \\
\hline Female & $1.1(0.6-1.2)$ & $1.02(0.3-3.2)$ \\
\hline \multicolumn{3}{|l|}{ Marital status } \\
\hline Single & 1 & 1 \\
\hline Married/living together & $0.6(0.3-1.4)$ & $0.6(0.1-3.2)$ \\
\hline Separated/Widowed & $0.7(0.3-1.4)$ & $1.5(0.3-9.2)$ \\
\hline \multicolumn{3}{|l|}{ Religion } \\
\hline Roman Catholic & 1 & 1 \\
\hline Protestant/Pentecostal & $0.9(0.5-1.5)$ & $1.2(0.4-4.4)$ \\
\hline Muslim & $0.9(0.47-1.8)$ & $1.2(0.3-4.4)$ \\
\hline \multicolumn{3}{|l|}{ Tribe } \\
\hline Ganda & 1 & 1 \\
\hline Munyankole/Mutooro & $0.8(0.4-1.7)$ & $1.6(0.3-7.85)$ \\
\hline Rwandese & $0.8(0.4-1.4)$ & $0.8(0.2-3.3)$ \\
\hline \multicolumn{3}{|l|}{ Education } \\
\hline None & 1 & 1 \\
\hline Primary & $0.7(0.4-1.4)$ & $0.5(0.1-2.7)$ \\
\hline Post primary & $1.1(0.5-2.4)$ & $0.8(0.1-5.3)$ \\
\hline \multicolumn{3}{|l|}{ Residence } \\
\hline Rural & 1 & 1 \\
\hline Semi-Urban & $1.0(0.6-1.6)$ & $0.2(0.1-0.9)$ \\
\hline \multicolumn{3}{|l|}{ Occupation } \\
\hline Formal & 1 & 1 \\
\hline Peasant & $1.6(0.75-3.6)$ & $7.9(1.4-46.2)$ \\
\hline Business & $1.7(0.68-4.1)$ & $8.7(1.2-61.7)$ \\
\hline \multicolumn{3}{|l|}{ Income level (USD) } \\
\hline$<20$ & 1 & 1 \\
\hline $20-40$ & $0.9(0.5-1.7)$ & $1.4(0.4-4.9)$ \\
\hline$>40$ & $1.4(0.7-2.9)$ & $6.4(1.2-34.7)$ \\
\hline \multicolumn{3}{|l|}{ On ART } \\
\hline Yes & 1 & 1 \\
\hline № & $1.16(0.6-2.4)$ & $0.5(0.1-3.1)$ \\
\hline \multicolumn{3}{|l|}{ Period in HIV care in years } \\
\hline$<1$ & 1 & 1 \\
\hline$\geq 1$ & $1.13(0.6-2.0)$ & $0.4(0.1-2.1)$ \\
\hline \multicolumn{3}{|l|}{ Distance to health facility in $\mathrm{km}$} \\
\hline$<10$ & 1 & 1 \\
\hline$\geq 10$ & $1.5(0.9-2.5)$ & $2.4(0.8-7.2)$ \\
\hline \multicolumn{3}{|l|}{ Ever sought VHT services } \\
\hline Yes & 1 & 1 \\
\hline No & $1.3(0.8-2.0)$ & $1.1(0.4-3.3)$ \\
\hline \multicolumn{3}{|l|}{ Peer encouragement } \\
\hline Yes & 1 & 1 \\
\hline No & 22.5 (9.9-51.1) & $6.3(1.4-28.1)$ \\
\hline \multicolumn{3}{|l|}{ Spouse/partner encouragement } \\
\hline Yes & 1 & 1 \\
\hline No & $20.2(8.8-46.3)$ & $4.9(1.2-19.8)$ \\
\hline \multicolumn{3}{|l|}{ Community leader encouragement } \\
\hline Yes & 1 & 1 \\
\hline № & $15.1(7.5-30.4)$ & $9.7(3.4-27.9)$ \\
\hline
\end{tabular}

Factors associated with willingness of PLWHAs to couragement (OR 22.5 95\% CI 9.9-51.1), spouse/partner utilize HIV services provided by HIV positive VHTs encouragement (OR 20.22 95\% CI 8.8-46.3) and comin Kalungu district munity leader encouragement (OR 15.1 95\% CI 7.5-30.4) At bivariate analysis, PLWHAs who did not have peer en- were less likely to utilize HIV services provided by VHTs 
irrespective of their HIV status (Table 2). There was no significant association between time spent in HIV care and management, distance form health facility, income level, residence or occupation and utilization of HIV services provided by VHTs at bivariate analysis.

Predictors of willingness of PLWHAs to utilize HIV services provided by HIV positive VHTs in Kalungu district After adjusting for confounders at multivariable analysis, PLWHAs living in urban areas were $20 \%$ more likely to utilize HIV services provided by VHTs (Adjusted OR
0.2 95\% CI 0.1-0.9). Barriers to utilizing HIV services provided by VHTs included income level of greater than USD 40 (Adjusted OR 6.4 95\% CI 1.2-34.7), being a business person (adjusted OR $8.7195 \%$ CI 1.23-61.72), being a small-scale farmer (Adjusted OR 7.9 95\% CI 1.4-46.2) lack of peer encouragement (Adjusted OR 6.3 95\% CI 1.4-28.1), lack of encouragement from spouse (Adjusted OR $4.995 \%$ CI 1.2-19.8) and lack of encouragement from community leader (Adjusted OR 9.7 95\% CI 3.427.9) (Table 3).

Table 3: Proportion of PLWHAs willing to utilize HIV services in Kalungu, Uganda, 2014

\begin{tabular}{ccc}
\hline Outcome & $\begin{array}{c}\text { Frequency, } \mathbf{n} \\
(\mathbf{N}=312)\end{array}$ & Percentage (95\%CI) \\
\hline Willingness from VHTs* & & $49.0(43.4-54.6)$ \\
Willing & 152 & $50.9(45.4-56.6)$ \\
Not willing & 158 & $75.6(70.8-80.4)$ \\
Willingness from HIV positive VHT* & & $24.4(19.6-29.2)$ \\
Willing & 235 & \\
Not willing & 76 & \\
*2 missing willingness from VHTs and 1 missing Willingness from HIV positive VHTs & \\
\hline
\end{tabular}

\section{Discussion}

In this study, the approximately threefold increase observed on willingness by VHT who were HIV positive to utilize HIV services (Table 4) was comparable to related studies done elsewhere in Uganda ${ }^{16,17}$. Community support provided to community health workers through task shifting of specific supervised roles in ART programs revealed an increase in acceptability for HIV services at facility level in rural South Africa ${ }^{17,18}$. This may have been due to the fact that HIV positive people will easily associate with their fellow HIV positive VHTs. However, these studies were conducted among the general population as opposed to this current study where all participants were HIV positive prior to recruitment ${ }^{16}$. The increase in willingness when the VHTs was HIV positive may have been due to the confidence the PLWHAs have amongst their peers of the same HIV status ${ }^{19}$.

This kind of confidence perceived may be a result of the PLWHA feeling secure when disclosing to their counterparts $^{20}$. Systematic reviews done about the work of VHTS in improving HV care and management for PLWHA in SSA revealed that VHT clearly enhance uptake of HIV services if appropriate training is provided to them to understand their roles in HIV care and management ${ }^{21}$. Such models may reduce reduced work load among the health workers and also reduced waiting time for the eligible clients for HIV services ${ }^{22}$. This will enable Uganda increase the number of PLWHA receiving ART ${ }^{23,24}$. Policy makers therefore need to consider inclusion of the HIV services in thecommunity health workers program at the district level to increase uptake of HIV services in communities with high HIV prevalence rates ${ }^{25}$. Other studies have also documented the support from various stake holders in the fight against HIV/AIDS for task shifting to community level to reduce the waiting time and work load among health workers attending to these patients ${ }^{26,27}$. However for such task shifting to be effective, community programs need to be driven, owned by and embedded in the communities. Still, an enabling and supportive environment is needed to ensure that task shifting to lay staff and PLWHA is effective and quality services are provided. Finally, a long term vision and commitment from national governments and international donors is required ${ }^{28}$.

Findings in this study were comparable to earlier studies done on the role of social and community support and HIV service delivery ${ }^{27,29}$. Peer encouragement, partner support and community leader encouragement were associated with PLWHAs willingness to utilize HIV ser- 
vices provided by community health workers due to the strong bonds created between the PLWHAs and their relatives. In Uganda still, partner support is crucial and has also been associated with increased use of other maternal and child health services for example of skilled birth delivery $^{30}$ and family planning use ${ }^{31}$. In addition, because of stigma PLWHAs tend to disclose their status to their peers in the HIV clinics. VHTs have also been found to offer a conducive environment for disclosure in other parts of Africa ${ }^{32-34}$. Social structures enable PLWHAs to cope and even disclose to other people improving adherence to care and treatment ${ }^{35-37}$.

Our study had limitations hence interpretation of findings should be done in light of these. This was a cross-sectional study hence casual temporality could not be ascertained. Recall bias could have arisen since the participants were expected to recollect occurance of past events. We controlled for potential confounders such as socio-demographic characteristics in the multi-variable analysis. Some questionnaires were incomplete and also some particpants opted to withdraw before completion of the interviews.

\section{Conclusion}

HIV positive patients are willing to use HIV services provided by Community health volunteers. However, consideration may be given to HIV positive VHTs with whom the HIV positive clients can easily associate with.

Acknowledgements: Financial support was provided by the Department for International Development of the UK Government through the British Medical Research Council to conduct this study. Kalungu district provided the institutional framework for this study to be conducted.

\section{References}

1. UNAIDS. Global Report-UNAIDS Report on Global AIDS Epidemic 2013/http://www.google. $\mathrm{com} / \mathrm{url}$ ? sa $=\mathrm{t} \& \mathrm{rct}=\mathrm{j} \& \mathrm{q}=\&$ esrc $=\mathrm{s} \&$ source $=$ web\&c$\mathrm{d}=1$ \&ved $=0$ CCoQFjAA\&url $=$ http $\% 3 \mathrm{~A} \% 2 \mathrm{~F} \% 2 \mathrm{Fwww}$. unaids.org $\% 2 \mathrm{Fen} \% 2 \mathrm{Fmedia} \% 2 \mathrm{Funaids} \% 2 \mathrm{Fcontentas}$ sets $\% 2$ Fdocuments $\% 2 F$ epidemiology $\% 2 F 2013 \% 2 F$ gr2013\%2FUNAIDS_Global_Report_2013_en.pd$\mathrm{f} \& \mathrm{i}=1 \mathrm{veqVMXOG}$ cneaLjygegO\&usg $=\mathrm{AFQjCNH}$ 9ox1sW4Af9x61I07_wa_Kqz7_mg\&sig2=ROgfaJFMjIqAJ1AlU4Mm4A\&bvm=bv.82001339,d.d2s. 2013;1(1):198.
2. MoH-Uganda. AIDS indicator survey. 2013;1(1):198.

3. Amouzou A, Morris S, Moulton LH, Mukanga D. Assessing the impact of integrated community case management (iCCM) programs on child mortality: Review of early results and lessons learned in sub-Saharan Africa. $J$ Glob Health. 2014;4(2):020411.

4. Rasanathan K, Muniz M, Bakshi S, Kumar M, Solano A, Kariuki W, et al. Community case management of childhood illness in sub-Saharan Africa - findings from a cross-sectional survey on policy and implementation. $J$ Glob Health. 2014;4(2):020401.

5. Mwai GW, Mburu G, Torpey K, Frost P, Ford N, Seeley $\mathrm{J}$. Role and outcomes of community health workers in HIV care in sub-Saharan Africa: a systematic review. Journal of the International AIDS Society. 2013;16:18586.

6. Bemelmans M, Baert S, Goemaere E, Wilkinson L, Vandendyck M, van Cutsem G, et al. Community-supported models of care for people on HIV treatment in sub-Saharan Africa. Trop Med Int Health. 2014;19(8):96877. PubMed

7. Rasschaert F, Decroo T, Remartinez D, Telfer B, Lessitala F, Biot M, et al. Sustainability of a community-based anti-retroviral care delivery model - a qualitative research study in Tete, Mozambique. J Int AIDS Soc. 2014;17:18910. 8. Aantjes C, Quinlan T, Bunders J. Integration of community home based care programmes within national primary health care revitalisation strategies in Ethiopia, Malawi, South-Africa and Zambia: a comparative assessment. Global Health. 2014;10(1):85.

9. Callaghan M, Ford N, Schneider H. A systematic review of task- shifting for HIV treatment and care in Africa. Hum Resour Health. 2010;8:8.

10. Uebel KE, Nash J, Avalos A. Caring for the caregivers: models of HIV/AIDS care and treatment provision for health care workers in Southern Africa. I Infect Dis. 2007;196 Suppl 3:S500-4.

11. Parry MF, Stewart J, Wright P, McLeod GX. Collaborative management of HIV infection in the community: an effort to improve the quality of HIV care. AIDS Care. 2004;16(6):690-9.

12. Thirumurthy H, Chamie G, Jain V, Kabami J, Kwarisiima D, Clark TD, et al. Improved employment and education outcomes in households of HIV-infected adults with high CD4 cell counts: evidence from a community health campaign in Uganda. AIDS. 2013;27(4):627-34. 13. Jain V, Liegler T, Kabami J, Chamie G, Clark TD, Black D, et al. Assessment of population-based HIV RNA lev- 
els in a rural east African setting using a fingerprick-based blood collection method. Clin Infect Dis. 2013;56(4):598 $-605$.

14. Kish L. Sampling organizations and groups of unequal sizes. American sociological review. 1965:564-72.

15. Naik R, Tabana H, Doherty T, Zembe W, Jackson D. Client characteristics and acceptability of a home-based HIV counselling and testing intervention in rural South Africa. BMC Public Health. 2012;12:824.

16. Chamie G, Kwarisiima D, Clark TD, Kabami J, Jain V, Geng E, et al. Uptake of community-based HIV testing during a multi-disease health campaign in rural Uganda. PloS one. 2014;9(1): e84317.

17. Decroo T, Rasschaert F, Telfer B, Remartinez D, Laga M, Ford N. Community-based antiretroviral therapy programs can overcome barriers to retention of patients and decongest health services in sub-Saharan Africa: a systematic review. International health. 2013;5(3):169-79.

18. Bedelu M, Ford N, Hilderbrand K, Reuter H. Implementing antiretroviral therapy in rural communities: the Lusikisiki model of decentralized HIV/AIDS care. Journal of Infectious Diseases. 2007;196(Supplement 3):S464-S8. 19. Kunihira NR,Nuwaha F, Mayanja R, Peterson S. Barriers to use of antiretroviral drugs in Rakai district of Uganda. Afr Health Sci. 2010;10(2):120-9. PubMed

20. Nattabi B, Li J, Thompson SC, Orach CG, Earnest J. Factors associated with perceived stigma among people living with HIV/AIDS in post-conflict northern Uganda. AIDS education and prevention : official publication of the International Society for AIDS Education. 2011;23(3):193205.

21. Mwai GW, Mburu G, Torpey K, Frost P, Ford N, Seeley J. Role and outcomes of community health workers in HIV care in sub-Saharan Africa: a systematic review. Journal of the International AIDS Society. 2013;16(1).

22. Alamo S, Wabwire-Mangen F, Kenneth E, Sunday P, Laga M, Colebunders RL. Task-shifting to community health workers: evaluation of the performance of a peerled model in an antiretroviral program in Uganda. AIDS patient care and STDs. 2012;26(2):101-7.

23. Duber HC, Dansereau E, Masters SH, Achan J, Burstein R, DeCenso B, et al. Uptake of WHO recommendations for first-line antiretroviral therapy in Kenya, Uganda, and Zambia. PloS one. 2015;10(3): e0120350.

24. Mujugira A, Celum C, Thomas KK, Farquhar C, Mugo N, Katabira E, et al. Delay of antiretroviral therapy initiation is common in East African HIV-infected individuals in serodiscordant partnerships. Journal of acquired immune deficiency syndromes (1999). 2014;66(4):436-42.

25. Hermann K, Van Damme W, Pariyo GW, Schouten E, Assefa Y, Cirera A, et al. Community health workers for ART in sub-Saharan Africa: learning from experience--capitalizing on new opportunities. Hum Resour Health. 2009;7:31.

26. Haacker M. Financing HIV/AIDS programs in sub-Saharan Africa. Health Aff (Millwood). 2009;28(6):1606-16. 27. Alamo ST, Wagner GJ, Ouma J, Sunday P, Marie L, Colebunders R, et al. Strategies for optimizing clinic efficiency in a community-based antiretroviral treatment programme in Uganda. AIDS Behav. 2013;17(1):274-83. PubMed

28. Decroo T, Koole O, Remartinez D, dos Santos N, Dezembro S, Jofrisse M, et al. Four-year retention and risk factors for attrition among members of community ART groups in Tete, Mozambique. Trop Med Int Health. 2014;19(5):514-21. PubMed

29. Mayanja BN, Ekoru K, Namugenyi H, Lubega R, Mugisha JO. Patients' worries before starting antiretroviral therapy and their association with treatment adherence and outcomes: a prospective study in rural Uganda, 2004 - 2009. BMC Res Notes. 2013;6:187.

30. TweheyoRaymond JK-L, Nazarius M Tumwesigye, Juliet N Sekandi. Male partner attendance of skilled antenatal care in peri-urban Gulu district, Northern Uganda. Biomed Central. 2010.

31. Anguzu R, Tweheyo R, Sekandi JN, Zalwango V, Muhumuza C, TusiimeS, et al. Knowledge and attitudes towards use of long acting reversible contraceptives among women of reproductive age in Lubaga division, Kampala district, Uganda. BMC research notes. 2014;7(1):153 .

32. Ncama BP, McInerney PA, Bhengu BR, Corless IB, Wantland DJ, Nicholas PK, et al. Social support and medication adherence in HIV disease in KwaZulu-Natal, South Africa. Int J Nurs Stud. 2008;45(12):1757-63. PubMed

33. Ncama BP. Models of community/home-based care for people living with HIV/AIDS in Southern Africa. $J$ Assoc Nurses AIDS Care. 2005;16(3):33-40.

34. Ncama BP. Acceptance and disclosure of HIV status through an integrated community/home-based care program in South Africa. Int Nurs Rev. 2007;54(4):391-7. PubMed 
35. Watt MH, Maman S, Jacobson M, Laiser J, John M. discrimination in five international sites: the influence of Missed opportunities for religious organizations to support people living with HIV/AIDS: findings from Tanzacare and treatment resources in high prevalence settings. Soc Sci Med. 2009;68(12):2271-8. PubMed

nia. AIDS Patient Care STDS. 2009;23(5):389-94. PubMed 37. Maman S, van Rooyen H, Groves AK. HIV status 36. Maman S, Abler L, Parker L, Lane T, Chirowodza A, Ntogwisangu J, et al. A comparison of HIV stigma and disclosure to families for social support in South Africa (NIMH Project Accept/HPTN 043). AIDS Care. 2014;26(2):226-32. PubMed 